\title{
Penerapan Finite State Automata Pada Vending Machine Parfum Laundry Pakaian
}

\author{
Yessica Fara Desvia ${ }^{1, *}$, Rosadi Rosadi ${ }^{1}$, Frieyadie Frieyadie ${ }^{2}$, Tuti Haryanti ${ }^{2}$, \\ Windu Gata 1 \\ 1 IImu Komputer; Universitas Nusa Mandiri; Jl. Jatiwaringin Raya No. 2, Jakarta Timur 13620, \\ Telp (021) 2853447 / 28534390; e-mail: 14207118@nusamandiri.ac.id, \\ 14207036@nusamandiri.ac.id, windu@nusamandiri.ac.id \\ 2 Sistem Informasi; Universitas Nusa Mandiri; Jl. Jatiwaringin Raya No. 2, Jakarta Timur 13620, \\ Telp (021) 2853447 / 28534390; e-mail: frieyadie@nusamandiri.ac.id, tuti@nusamandiri.ac.id \\ * Korespondensi: e-mail: 14207118@nusamandiri.ac.id
}

Diterima: 14 Agustus 2021; Review: 20 Agustus 2021; Disetujui: 23 Agustus 2021

Cara sitasi: Desvia YF, Rosadi R, Frieyadie F, Haryanti T, Gata W. 2021. Penerapan Finite State Automata Pada Vending Machine Parfum Laundry Pakaian. Bina Insani ICT Journal. Vol. 8 (2): 103-112.

\begin{abstract}
Abstrak: Parfum banyak digemari oleh berbagai kalangan, salah satunya adalah parfum laundry. Parfum laundry memiliki berbagai macam varian aroma, meliputi aroma buah, aroma bunga, aroma perpaduan buah dan bunga, dan aroma kayu-kayuan. Parfum laundry ini merupakan rangkaian akhir dalam proses laundry. Saat ini pelanggan menerima hasil laundry dengan aroma parfum yang dipilih secara random sesuai ketersediaan pihak laundry, hal ini menjadi masalah karena pelanggan tidak dapat memilih aroma parfum laundry sesuai dengan keinginan mereka. Dengan alasan tersebut maka diperlukan suatu rancangan sebuah Vending Machine (VM), rancangan VM ini menggunakan metode Finite State Automata (FSA) dengan jenis Non-Deterministic Finite Automata (NFA), metode tersebut digunakan karena dapat mengakomodir lebih dari satu kondisi dalam satu pilihan. Metode FSA jenis NFA dibuat dengan tahapan analisa proses bisnis, diagram state, desain VM dan pengujian. Hasil dari penelitian ini dengan adanya VM pemilihan parfum laundry pakaian, maka mempermudah pelanggan untuk dapat memilih parfum laundry sehingga pelanggan memperoleh hasil laundry dengan aroma parfum sesuai pilihan mereka.
\end{abstract}

Kata kunci: finite state automata, parfum laundry, vending machine

\begin{abstract}
Perfume is much favored by various circles, one of which is laundry perfume. Laundry perfume has a wide range of scent variants, including fruity scents, floral scents, fruity floral scents, and woody scents. This laundry perfume is the final line in the laundry process. Currently customers receive laundry results with perfume scents selected randomly according to the availability of the laundry party, this is a problem because customers cannot choose laundry perfume scents according to their wishes. For this reason, it is necessary to design a Vending Machine (VM), this VM design uses the Finite State Automata (FSA) method with the NonDeterministic Finite Automata (NFA) type, this method is used because it can accommodate more than one condition in one choice. The FSA type of NFA method is made with the stages of business process analysis, state diagrams, VM design and testing. The results of this study with the VM in the selection of clothes laundry perfume, it makes it easier for customers to be able to choose laundry perfumes so that customers get laundry results with the perfume scent of their choice.
\end{abstract}

Keywords: finite state automata, laundry perfume, vending machine 


\section{Pendahuluan}

Pada filosofi Jawa yang paling utama atau yang paling pertama kita sebut adalah sandang atau pakaian, setelah itu baru kebutuhan lainnya. Sandang (pakaian) yang bersih, rapi dan wangi akan sangat menunjang penampilan, sehingga manusia akan memberikan perhatian yang khusus terhadap pakaian yang dikenakan. Agar memberikan kenyamanan pada saat berinteraksi dengan sesama maka perlu dengan adanya penggunaan parfum.

Parfum merupakan sebuah produk yang sering kita dengar dalam kehidupan seharihari. Masyarakat mempunyai selera aroma wangi yang berbeda-beda, ada yang suka dengan aroma bunga, aroma buah, perpaduan antara aroma buah dan bunga, bahkan ada yang suka aroma kayu-kayuan dan masih banyak lagi[1].

Dalam menciptakan keharuman yang mampu bertahan lama, sifat tahan lama parfum diperoleh dengan memberikan bahan yang kita sebut fixative (pengikat) parfum. Bibit parfum terdapat tingkat volatilitas yang sangat baik sehingga dapat membuat aroma parfum pada pakaian tidak dapat bertahan lama, sehingga dengan memberikan bahan fixative (pengikat) mampu menekan laju volatilitas parfum tersebut.[2]

Salah satu produk dari parfum adalah parfum laundry. Parfum laundry ini digunakan pada tahap akhir dalam proses jasa laundry. Jasa laundry sangat diminati oleh banyak masyarakat, hal ini dapat diketahui dari hasil survei berita cetak harian yang menyatakan bahwa pangsa pasar paling besar laundry kiloan ialah mahasiswa dengan jumlah persentase sebanyak $48 \%$, pekerja dengan jumlah persentase sebanyak $32 \%$, ibu rumah tangga dengan jumlah persentase sebanyak $16 \%$, dan lain-lain dengan jumlah persentase sebanyak 4\% [3].

Laundry Depatemen atau Laundry Section itu sendriri merupakan bagian di hotel atau bagian dari pada pembenahan yang mampu bertanggung jawab atas pencucian seluruh bahan pakaian baik itu cucian rumah juga cucian tamu. Saat ini untuk menjalankan operasionalnya, laundry dapat pula melayani pencucian baik dari cucian luar dengan tujuan agar memperoleh keuntunggan [4].

Menggunakan jasa laundry salah satu jalan alternatif bagi masyarakat yang memiliki jadwal rutinitas yang padat, karena selain praktis bisa mencuci pakaian dapat juga sepaket dengan jasa setrika, sehingga dapat meringankan kewajiban dari masyarakat yang tidak mempunyai waktu untuk mencuci pakaian ataupun menyetrika pakaian kerja maupun pakaian sehari-hari mereka.

Masyarakat saat ini dapat menggunakan jasa laundry dengan manual maupun daring dan pada umumnya sudah berjalan dengan baik, hanya saja dalam jasa laundry terdapat kelemahan yaitu masyarakat yang menggunakan jasa laundry tidak dapat memilih aroma parfum sesuai dengan keinginan mereka. Masyarakat selama ini hanya menerima hasil laundry yang sudah rapi, bersih dan wangi. Dengan ini akan membuat tingkat kepuasan masyarakat kurang maksimal.

Selain menggunakan jasa laundry secara daring, untuk menunjang perkembangan sebuah bisnis laundry, juga dapat dirancang sebuah sistem Vending Machine (VM). Sehingga masyarakat yang ingin menggunakan jasa laundry dapat memilih aroma parfum sesuai dengan keinginan mereka. Secara umum VM berwujud kotak terbuat dari besi yang dalam bagian depan terdapat istilah-istilah supaya produk bisa terlihat oleh pemakai. Selama ini VM banyak digunakan untuk menjual barang maupun produk, antara lain: minuman dan makanan kemasan, tiket kereta dan lain-lain [5].

Pada penelitian sebelumnya, VM dirancang untuk penjualan susu kambing etawa dengan berbagai varian rasa yang menggunakan metode FSA dengan jenis NFA, dikarenakan penjualan susu kambing etawa belum merata maka VM pada penjualan susu kambing etawa ini dapat membantu penyebaran produk khususnya bagi masyarakat kota besar [5].

Selain itu VM juga dirancang untuk menjual produk rujak buah dengan menggunakan metode FSA jenis NFA, metode tersebut menghasilkan desain VM yang dapat menerima masukkan serta memilih berbagai macam jenis buah-buahan dan bumbu rujak dengan berbagai level kepedasan sesuai keinginan mereka, sehingga dengan adanya VM penjualan rujak buah dapat diharapkan meningkatkan nilai jual dan dapat menarik konsumen lebih luas lagi [6].

Penelitian lainnya VM dirancang untuk menjual berbagai macam produk jamu dan menjual berbagai macam produk yoghurt dengan metode FSA jenis NFA yang menyimpulkan bahwa FSA dapat dijadikan landasan dasar untuk membangun sebuah VM, dengan usulan penggunaan state yang sedikit dan penggunaan uang kertas sebagai masukkan [7][8][9]. 
Penelitian lain yang telah dipublikasikan oleh [10] menyimpulkan dengan adanya metode NFA dapat menjadi salah satu alternatif dalam membuat rancangan VM kopi. Proses untuk meracik kopi dan pembayaran kopi dikerjakan secara langsung, sehingga akan mengeluarkan produk yang sesuai.

VM selain menjual makanan dan minuman, terdapat penelitian tentang VM dengan metode FSA jenis NFA yang menjual produk rokok tetapi terintegrasi dengan e-KTP bertujuan mengurangi peredaran rokok pada usia dini sehingga penjualan produk rokok yang terintegrasi dengan e-KTP dapat terkendali dengan baik [11].

Penelitian ini akan membahas mengenai pemilihan parfum laundry yang belum pernah diterapkan pada penelitian sebelumnya. Pada desain VM pemilihan parfum laundry ini, masyarakat dapat menggunakannya sepaket dengan jasa laundry. Desain VM ini di dalamnya menerapkan metode Finite State Automata (FSA) jenis Non-Deterministic Finite Automata (NFA). Sehingga akan menjadi sebuah solusi baru dalam jasa laundry selain memilih parfum laundry, masyarakat juga dapat membayar dengan tunai ataupun non-tunai.

Tujuan dari penelitian ini adalah menyelesaikan sebuah permasalahan dimana masyarakat yang ingin menggunakan jasa laundry dapat memilih pula parfum laundry yang diinginkan sehingga menjadi kepuasan tersendiri bagi masyarakat. Hasil dari penelitian ini berupa VM pemilihan parfum laundry pakaian dengan metode FSA jenis NFA, agar dapat membatu mempermudah masyarakat untuk dapat memilih parfum laundry sehingga pakaian yang diterima wangi sesuai dengan aroma keinginan mereka. Dengan adanya VM ini, diharapkan menjadi salah satu penunjang perkembangan bisnis industri Laundry dan merupakan solusi alternatif bagi masyarakat yang ingin menggunakan jasa laundry.

\section{Metode Penelitian}

Metode yang digunakan dalam Penerapan FSA Pada VM Parfum Laundry ini terdapat pada gambar 1, yaitu Analisa Proses Bisnis Parfum Laundry Pakaian, Finite State Automata (FSA), Diagram State Parfum Laundry Pakaian, Desain VM Parfum Laundry Pakaian dan Pengujian VM Parfum Laundry Pakaian.

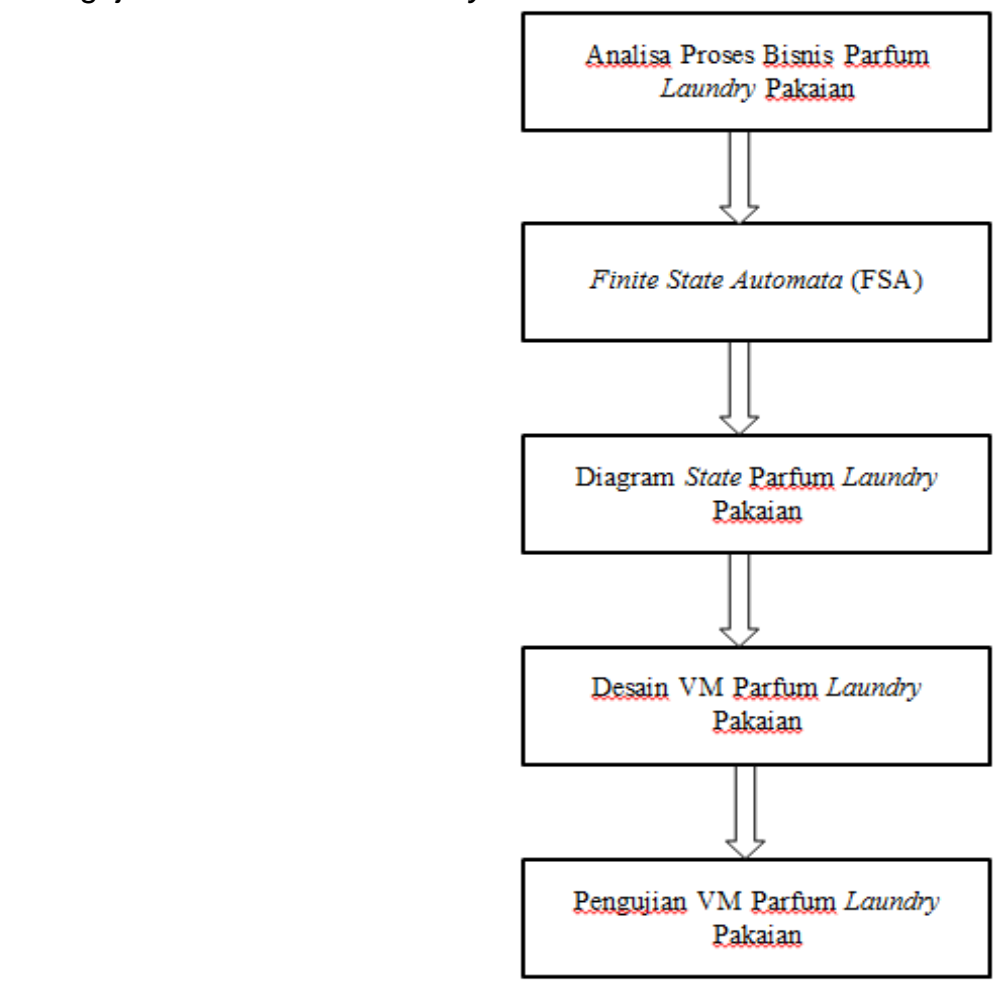

Sumber: Hasil Penelitian (2021)

Gambar 1. Metode Penelitian

Analisa proses bisnis dilakukan untuk mengetahui proses berjalan pada laundry baik secara manual maupun secara daring yang dilakukan oleh masyarakat, kemudian menguraikan dan menggambarkan FSA jenis NFA yang akan digunakan pada penelitian ini dan berfungsi 
sebagai alur proses pemilihan parfum laundry hingga proses laundry, selanjutnya merancang diagram state yang meliputi atribut-atribut pada sebuah mesin VM. Setelah menguraikan FSA dan merancang diagram state, tahap selanjutnya adalah menggambarkan desain VM dari sebuah mesin VM pemilihan parfum laundry dan yang terakhir yaitu tahap pengujian.

\section{Hasil dan Pembahasan}

Hasil dan Pembahasan pada penelitian ini meliputi proses bisnis yang sedang berjalan terpaut dengan jasa laundry, perancangan usulan sistem yang digambarkan kedalam bentuk diagram state dan perancangan desain antarmuka pada VM. Berikut uraian mengenai proses bisnis sistem yang berjalan.

\section{Proses Bisnis Parfum Laundry Pakaian}

Jasa laundry saat ini dapat melayani dengan cara manual ataupun dengan cara daring. Jasa laundry dengan cara manual yaitu pelanggan laundry datang ke tempat laundry dengan membawa pakian kotor kemudian pelanggan akan menyerahkan pakian kotor kepada petugas laundry, setelah petugas laundry menerima pakian kotor tersebut maka petugas laundry akan menimbang pakaian kotor. Setelah pakaian kotor ditimbang oleh petugas laundry, kemudian petugas laundry akan mencatat ke dalam nota berat daripada timbangan pakaian kotor tersebut. Petugas laundry juga akan menawarkan jenis jasa laundry kepada pelanggan, setelah pelanggan memilih jenis jasa laundry maka petugas akan menotalkan harga dari jenis jasa laundry yang telah dipilih dengan berat pakaian kotor, petugas laundry akan mencatat jumlah total bayar pada nota yang terdiri dari tiga rangkap, meliputi nota untuk pelanggan, nota untuk arsip petugas laundy dan nota untuk ditempel pada kantong pakaian kotor. Pelanggan dapat langsung membayar total bayar dan dapat pula membayarkannya pada saat laundry sudah selesai di proses.

Berbeda dengan cara manual, jasa laundry dengan cara daring pelanggan dapat menggunakan jasa laundry dengan cara memesan jasa, kemudian pelanggan memasukkan alamat rumah, tanggal dan waktu pengambilan pakaian kotor, setelah itu petugas laundry akan datang untuk mengambil pakaian ke lokasi pelanggan sesuai dengan alamat yang dimasukkan pelanggan, lalu pelanggan dapat membayar dengan cara transfer ke rekening atans nama jasa laundry tersebut. Pada saat proses laundry telah selesai, maka petugas laundry akan mengantarkan pakaian ke lokasi pelanggan sesuai dengan alamat yang dimasukan pelanggan.

\section{Finite State Automata (FSA)}

FSA adalah sebuah mesin automata yang berasal dari bahasa biasa dan merupakan contoh matematika menurut suatu sistem yang bisa menerima dan membentuk output juga mempunyai state berhingga banyaknya sehingga bisa berpindah dari state satu ke state lainnya, FSA ini mempunyai dua tipe yaitu tipe DFA (Deterministic Finite Automata) dan tipe NFA (Non-Deterministic Finite Automata) [12][13][5][14]. Dengan maksud mesin ini hanya dapat menandai, memperoleh dan menghasilkan dari masukkan nilai yang diberikan [15]. FSA dapat diterangkan pada 5 tupel yaitu $\mathrm{M}=(\mathrm{Q}, \Sigma, \delta, S, F)$ artinya:

$\mathrm{Q}=$ kumpulan state

$\Sigma=$ kumpulan atribut input

$\delta=$ fungsi transisi

$\mathrm{S}=$ state utama

$S \in Q F=$ kumpulan state puncak, $F \cap Q$ (jumlah state puncak pada sebuah FSA dapat $>1$ )

Terdapat perbedaan antara DFA dan NFA, perbedaanya adalah DFA dapat menerima sebuah masukkan dimana state yang dituju dari masukkan tersebut hanya ada satu, sedangkan pada NFA dapat menerima masukkan beberapa state yang akan dituju untu satu masukkan. Adapun perbedaan lainnya adalah FNA dapat menerima masukkan kosong sedangkan DFA tidak dapat menerima masukkan kosong [16].

NFA adalah generalisasi dari determinisme, jadi setiap DFA secara otomatis merupakan robot NFA [17]. Suatu NFA ialah tipe Finite State Machine (FSM) bilamana antara satu state selanjutnya tidak seutuhnya ditentukan pada arus state maupun masukkan. Kumpulan berdasarkan kemungkinan state selanjutnya menyebutkan bahwa sebuah automata bisa beralih berdasarkan dari state awal (qa) kemudian ke state yang akan dituju (qb) menjadi ulasan atas suatu masukkan ( $\alpha$ ). Pada NFA, banyaknya state awal dan perubahan pada tiaptiap kumpulan atribut masukkan ( $\Sigma$ ) tidak wajib persis satu. [18] 


\section{Diagram State Parfum Laundry Pakaian}

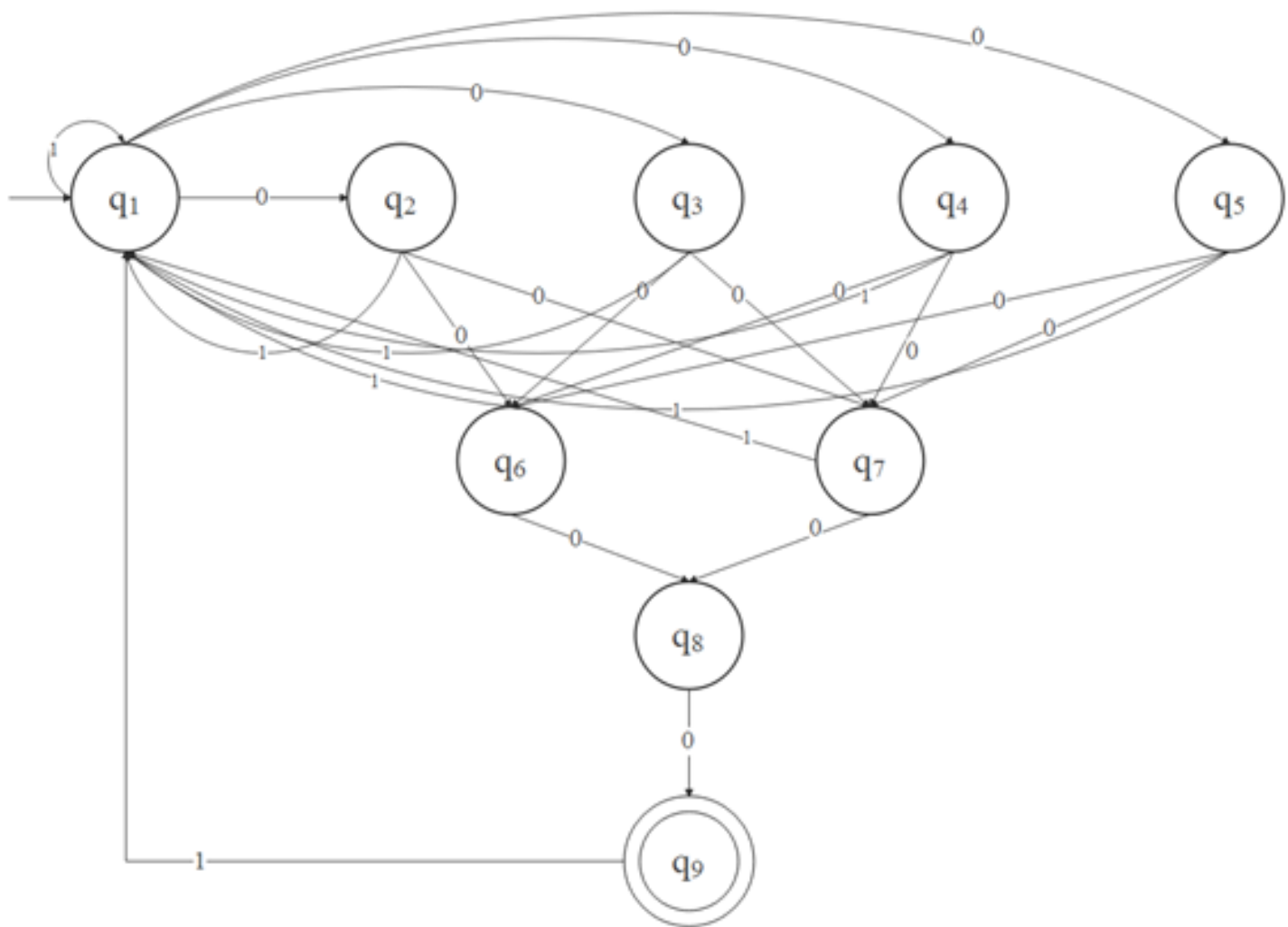

Sumber: Hasil Penelitian (2021)

Gambar 2. Diagram State Parfum Laundry berikut:

Pada gambar 2 diagram state parfum laundry, konfigurasi mesin dijelaskan sebagai $\mathrm{Q}=\left\{\mathrm{q}_{1}, \mathrm{q}_{2}, \mathrm{q}_{3}, \mathrm{q}_{4}, \mathrm{q}_{5}, \mathrm{q}_{6}, \mathrm{q}_{7}, \mathrm{q}_{7}, \mathrm{q}_{8}, \mathrm{q}_{9}\right\}$

Diagram state parfum laundry, mesin terdapat sejumlah state yang memiliki atribut proses, antara lain:

Tabel 1. Atribut Proses

\begin{tabular}{cl}
\hline Singkatan & Keterangan \\
\hline $\mathrm{q}_{1}$ & State aw al \\
\hline $\mathrm{q}_{2}$ & Aroma buah \\
\hline $\mathrm{q}_{3}$ & Aroma bunga \\
\hline $\mathrm{q}_{4}$ & Aroma buah dan bunga \\
\hline $\mathrm{q}_{5}$ & Aroma kayu-kayuan \\
\hline $\mathrm{q}_{6}$ & Pembayaran tunai \\
\hline $\mathrm{q}_{7}$ & Pembayaran Non-tunai \\
\hline $\mathrm{q}_{8}$ & Proses laundry \\
\hline $\mathrm{q}_{9}$ & Keluar pakaian \\
\hline
\end{tabular}

Sumber: Hasil Penelitian (2021)

$\Sigma=\{0,1\}$

Diagram state parfum laundry, mesin terdapat sejumlah masukkan yang memiliki atribut proses, antara lain:

Tabel 2. Masukan

\begin{tabular}{cll}
\hline Singkatan & & Keterangan \\
\hline 0 & Simbol lanjut & \\
\hline 1 & Simbol berhenti & \\
\hline Sumber: Hasil Penelitian (2021) &
\end{tabular}


$\delta=$ fungsi transisi

$\delta\left(q_{1}, 1\right)=q_{1} ; \quad \delta\left(q_{1}, 0\right)=q_{2} ; \quad \delta\left(q_{1}, 0\right)=q_{3} ; \quad \delta\left(q_{1}, 0\right)=q_{4} ; \quad \delta\left(q_{1}, 0\right)=q_{5} ; \quad \delta\left(q_{2}, 1\right)=q_{1} ; \quad \delta\left(q_{2}, 0\right)=q_{6} ; \quad \delta\left(q_{2}, 0\right)=q_{7} ;$ $\delta\left(q_{3}, 1\right)=q_{1} ; \quad \delta\left(q_{3}, 0\right)=q_{6} ; \quad \delta\left(q_{3}, 0\right)=q_{7} ; \quad \delta\left(q_{4}, 1\right)=q_{1} ; \quad \delta\left(q_{4}, 0\right)=q_{6} ; \quad \delta\left(q_{4}, 0\right)=q_{7} ; \quad \delta\left(q_{5}, 1\right)=q_{1} ; \quad \delta\left(q_{5}, 0\right)=q_{6} ;$ $\delta\left(q_{5}, 0\right)=q 7 ; \delta\left(q_{6}, 1\right)=q_{1} ; \delta\left(q_{6}, 0\right)=q 8 ; \delta\left(q_{7}, 1\right)=q_{1} ; \delta(q 7,0)=q 8 ; \delta(q 8,0)=q 9 ; \delta(q 9,0)=\varnothing ; \delta(q 9,1)=\varnothing ;$ Berikut jika dipetakan ke dalam table transisi, maka:

Tabel 3. Transisi Diagram State

\begin{tabular}{|c|c|c|}
\hline Transisi & 0 & 1 \\
\hline$q_{1}$ & $q_{2}, q_{3}, q_{4}, q_{5}$ & $\mathrm{q}_{1}$ \\
\hline $\mathrm{q}_{2}$ & $q_{6}, q_{7}$ & $\mathrm{q}_{1}$ \\
\hline $\mathrm{q}_{3}$ & $q_{6}, q_{7}$ & $\mathrm{q}_{1}$ \\
\hline$q_{4}$ & $q_{6}, q_{7}$ & $\mathrm{q}_{1}$ \\
\hline$q_{5}$ & $q_{6}, q_{7}$ & $\mathrm{q}_{1}$ \\
\hline $\mathrm{q}_{6}$ & $\mathrm{q}_{6}, \mathrm{q}_{8}$ & $q_{1}$ \\
\hline$q_{7}$ & $\mathrm{q}_{8}$ & $\mathrm{q}_{1}$ \\
\hline$q_{8}$ & $q_{8}, q_{9}$ & - \\
\hline$q_{9}$ & $\varnothing$ & $\varnothing$ \\
\hline
\end{tabular}

Sumber: Hasil Penelitian (2021)

$S($ state awal $)=\left\{q_{1}\right\}$

$F($ final state $)=\{q 9\}$

Berdasarkan gambar 2 diagram state parfum laundry, dapat menerima masukkan berbentuk state yang tertuju disertai masukkan nol dan masukkan satu. Masukkan nol bermakna diagram state diatas akan lanjut ke state selanjutnya, sedangkan nemerima masukkan satu bermakna mesin sudah menangani tugasnya (telah mengeluarkan pakaian) lalu akan kembali pada state semula yaitu state awal. Mesin tersebut akan beroperasi jika masukkan yang dibaca berbanding dengan stateyang akan dituju.

Salah satu sampel alur diagram state diatas adalah state utama atau awal mesin akan meminta untuk memasukkan pakaian kotor kedalam mesin kemudian memilih parfum laundry yang diinginkan, misalnya memilih parfum laundry aroma kayu-kayuan, maka state utama atau awal yaitu q1 akan mengarah ke state q5, kemudian parfum laundry dipilih maka akan muncul pemilihan jenis metode pembayaran, apabila memilih metode pembayaran tunai maka akan menuju ke state $q_{6}$, apabila dalam pembayaran uang yang dimasukkan kurang dari total bayar, maka akan kembali ke state tersebut yaitu state $q 6$, setelah uang yang dimasukkan sesuai selanjutkan akan masuk ke state q8 untuk melakukan proses laundry, setelah proses laundry selesai maka akan lanjut ke state q9 yaitu mengeluarkan pakaian bersih dan wangi yang sudah dikemas rapi.

Apabila pada saat pembayaran metode yang dipilih non-tunai maka state q5 akan menuju ke state $\mathrm{q} 7$ untuk melakukan scan barcode, jika saldo tidak cukup maka proses laundry tidak akan terproses dengan baik dan akan kembali ke state awal yaitu ke state q1 beserta pakaian kotor akan keluar.

Jika dalam proses pemilihan parfum laundry yang dipilih stok sudah habis maka dari state q1 tidak akan melakukan proses atau tidak akan lanjut ke state berikutnya. Alur tersebut akan kembali ke state awal yaitu q1 beserta baju kotor yang sudah dimasukkan kedalam mesin akan kembali keluar.

Setiap parfum yang telah dipilih agar proses laundry berjalan maka harus membayarkan dengan memilih salah satu dari metode pembayaran yaitu tunai atau non-tunai yang sesuai dengan jumlah total bayar. Pada tabel 2 terdapat simbol $\varnothing$, simbol tersebut merupakan simbol hampa, dalam kasus ini symbol hampa berarti tidak ada kegiatan tau proses lain setelah pakaian keluar.

\section{Desain VM Parfum Laundry Pakaian}

Tampilan awal pada saat pelanggan datang yaitu akan menampilkan tampilan utama desain antar muka VM parfum laundry dengan tampilan kalimat yang bertuliskan Selamat datang, Silahkan memasukkan pakaian kotor Anda. Prinsip kerja VM parfum laundry ini, pertama pelanggan akan mendatangi mesin VM dan membawa pakaian kotor, setelah itu pelanggan akan memasukkan pakaian kotor ke dalam mesin dan mesin akan memproses. 

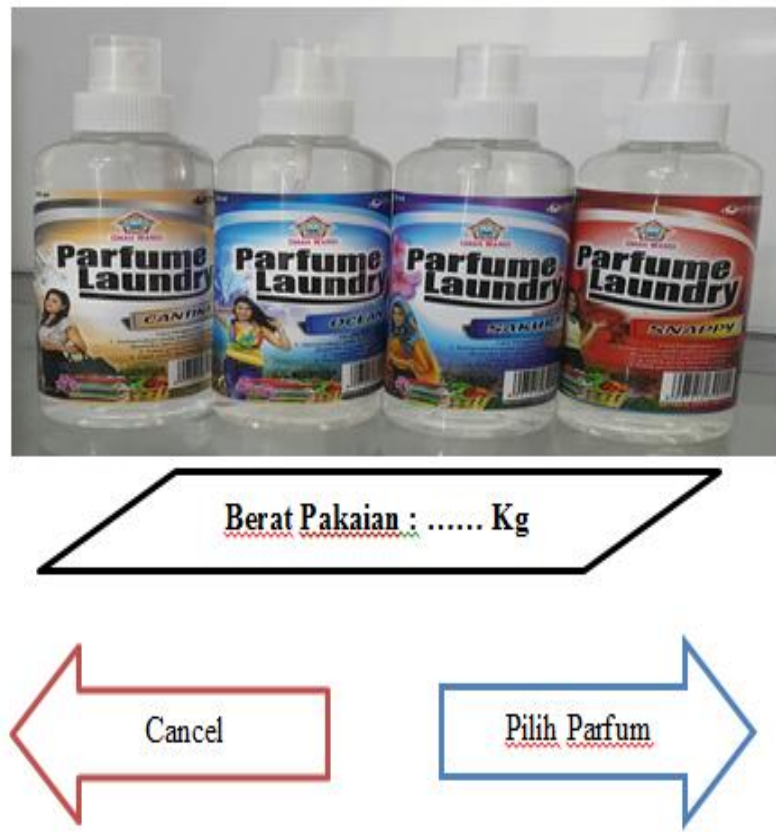

Sumber: Hasil Penelitian (2021)

Gambar 3. Tampilan VM Berat Pakaian

Kemudian pada tampilan gambar 3 , setelah mesin menerima pakaian kotor maka akan otomatis menimbang pakaian kotor tersebut dan pada tampilan layar VM akan tertera berat dari pakaian kotor tersebut. Pelanggan dapat melanjutkan proses selanjutnya dengan memilih menu Pilih Parfum, jika pelanggan tidak ingin melanjurkan proses maka pelanggan dapat memilih menu Cancel dan pakaian kotor akan kembali keluar.

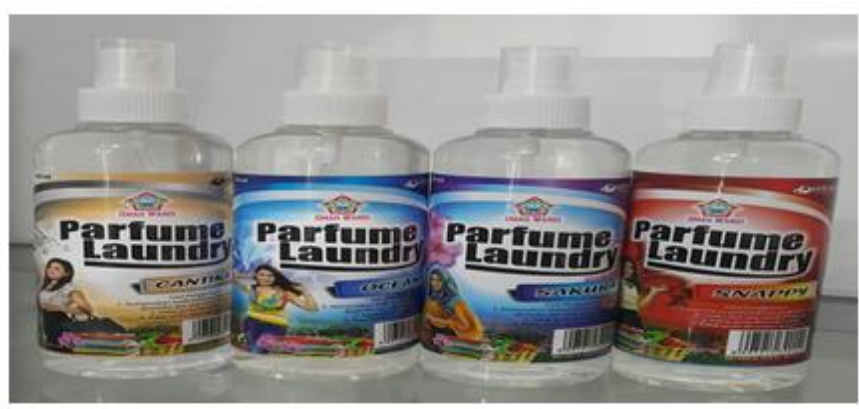

Pilih Aroma Parfum Laundry
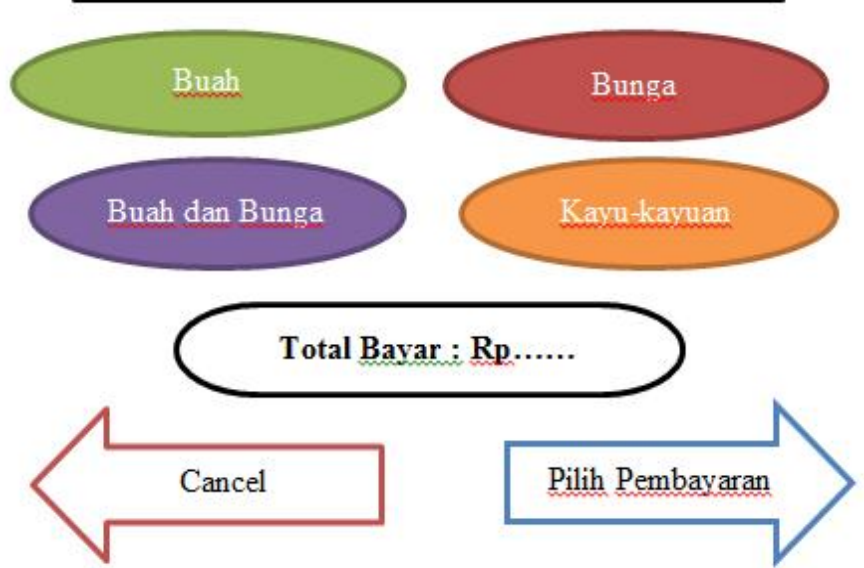

Sumber: Hasil Penelitian (2021)

Gambar 4. Tampilan VM Pemilihan Parfum 
Pada gambar 4 merupakan tampilan Pemilihan Parfum, pelanggan dapat memilih varian aroma parfum laundry sesuai yang diinginkan. Ikon parfum laundry yang telah dipilih akan menyala dan total bayar akan tampil pada mesin VM. Kemudian pelanggan dapat melanjutkan proses dengan memilih menu Pilih Pembayaran. Misalnya pelanggan memilih aroma parfum laundry Bunga, maka pada tampilan ikon Bunga yang ada pada mesin VM akan menyala dan otomatis Total Bayar akan tampil, selanjutnya pelanggan dapat memilih menu Pilih Pembayaran. Jika parfum yang dipilih stoknya habis maka ikon pada parfum tidak menyala dan pelanggan dapat membatalkan proses dengan cara memilih menu Cancel, kemudian pakaian kotor akan kembali keluar. Misalnya pelanggan memilih aroma perfum laundry Kayukayuan, sedangkan stok aroma Kayu-kayuan habis, maka ikon Kayu-kayuan yang ada pada mesin VM tidak akan menyala, sehingga ikon Total Bayar tidak akan menampilkan dan pelanggan dapat membatalkan proses.
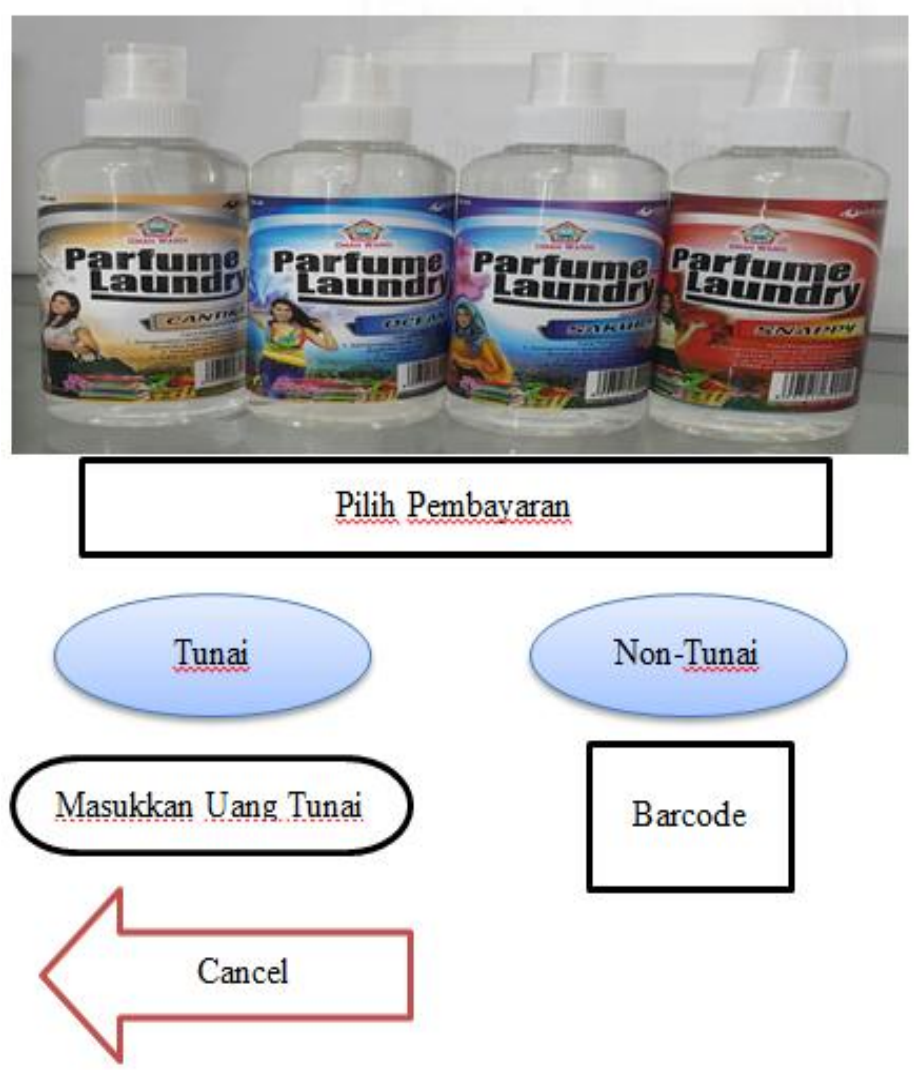

Sumber: Hasil Penelitian (2021)

Gambar 5. Tampilan VM Pemilihan Pembayaran

Tampilan VM pemilihan pembayaran yang ada pada gambar 5 merupakan metode pemabayaran yang ingin pelanggan gunakan. Terdapat dua metode pemilihan pembayaran yaitu tunai dan non-tunai. Jika pelanggan memilih metode pembayaran tunai, ikon Tunai pada VM akan menyala dan akan tampil pesan Masukkan Uang Tunai, maka pelanggan diminta untuk memasukkan uang tunai, apabila uang yang dimasukkan tidak sesuai dengan total bayar maka pelanggan dapat mengulangi dengan cara memilih pembayaran tunai pada ikon Tunai dan memsaukkan kembali uang tunai. Apabila pelanggan tidak membawa uang tunai lebih maka proses ini dapat dibatalkan dengan memilih menu Cancel, kemudian uang yang telah dimasukkan akan keluar beserta dengan pakaian kotor. Jika pelanggan memilih metode pembayaran non-tunai ikon Non-Tunai pada VM akan menyala dan barcode akan muncul, kemudian pelanggan dapat memindai barcode tersebut. Apabila saldo pelanggan tidak cukup maka pelanggan dapat membatalkan proses dengan memilih menu Cancel dan pakaian kotor akan kembali keluar.

Selanjutnya merupakan konfirmasi pembayaran dan proses laundry, pelanggan yang sudah membayar sesuai dengan total bayar menggunkan metode tunai ataupun non-tunai maka pada mesin VM akan menampilkan pesan Pembayaran Terkonfirmasi. Kemudian mesin 
VM akan memproses pakaian kotor tersebut, pada saat proses laundry sudah selesai maka pakaian bersih, wangi yang dikemas dengan rapi akan keluar dan apabila uang yang dimasukkan lebih dari total bayar maka uang kembalian beserta pakaian bersih, wangi yang dikemas dengan rapi akan keluar.

\section{Pengujian VM Parfum Laundry Pakaian}

Pada tahap pengujian VM Parfum Laundry Pakaian menggunakan cara verifikasi formal yaitu dengan model pengecekan. Dalam tahap ini dilakukan pengujian apakah desain VM ini sudah memenuhi yang diharapkan atau belum. Cara pengujian ini dilakukan dengan menyusun daftar kemungkinan terjadinya kesalahan. Urutan dalam pengujian sesuai dengan alur daftar yang telah disusun.

Tabel 4. Daftar Pengujian

\begin{tabular}{|c|c|c|}
\hline No & Pengujian & Keterangan \\
\hline \multirow{7}{*}{1} & \multirow{7}{*}{ Fungsi Aplikasi } & Kesesuaian keluaran laundrypakaian \\
\hline & & Kesesuaian keluaran uang kembalian \\
\hline & & Pengurangan isi stok parfum /aundry \\
\hline & & $\begin{array}{l}\text { Kesesuaian masukkan jenis parfumlaundry dengan keluaran w angi yang } \\
\text { dihasilkan }\end{array}$ \\
\hline & & Mengunci ikon jenis parfumlaundry yang dipilih \\
\hline & & Mengunci ikon pembayaran yang dipilih \\
\hline & & $\begin{array}{l}\text { Kesesuaian kotak pesan yang ditampilkan dengan masukkan ikon yang } \\
\text { dipilih }\end{array}$ \\
\hline \multirow{3}{*}{2} & \multirow{3}{*}{ Desain Antarmuka } & Aplikasi mudah digunakan \\
\hline & & Masukkan mudah digunakan \\
\hline & & Keluaran mudah dipahami pengguna \\
\hline
\end{tabular}

Sumber: Hasil Penelitian (2021)

\section{Kesimpulan}

Berdasarkan perancangan desain Vending Machine (VM) dengan menggunakan metode Finite State Automata (FSA) jenis Non-Deterministic Finite Automata (NFA), dapat ditarik kesimpulan bahwa penggunaan FSA jenis NFA dapat menjadi salah satu alternatif dalam merancang desain VM pemilihan parfum laundry. Metode NFA digunakan untuk mengambil pola masukkan tersebut menjadi suatu bahasa yang mudah dikenali oleh VM. Proses laundry beserta pemilihan pembayaran akan diproses secara langsung. VM selanjutnya akan mengeluarkan hasil laundry yang sudah dikemas dengan rapi dan wangi sesuai dengan keinginan mereka. Selain itu dapat memberikan dampak pada peningkatan perkembangan bisnis laundry.

\section{Referensi}

[1] D. P. Jailani and H. Patrie, "Analisa dan Rancangan Sistem Informasi Penjualan Parfum Berbasis E-Commerce pada Toko Seruni Parfum," J. Idealis, vol. 2, no. 5, pp. 98-105, 2019.

[2] K. N. A. B. Pramudono, "Studi Campuran Surfactant Untuk Menentukan Fungsi Solubilizer Dan Fixative Pada Industri Parfum,” J. Mipa, vol. 38, no. 1, pp. 57-67, 2016.

[3] R. Angelina, "Analisis Terhadap Keputusan Registrasi Member Simply Fresh Laundry Outlet 205 Blitar Untuk Meningkatkan Kepuasan Dan Loyalitas Pelanggan," Ris. Mhs. Ekon., vol. 3, no. 3, 2016.

[4] P. Kuswiyata, Mengenal Laundry, 1st ed. Yogyakarta: Deepublish, 2018.

[5] K. Handayani, D. Ismunandar, S. A. Putri, and W. Gata, "Penerapan Finite State Automata Pada Vending Machine Susu Kambing Etawa," Matics, vol. 12, no. 2, pp. 8792, 2021, doi: 10.18860/mat.v12i2.9270.

[6] R. A. Nugraha, A. Mulyani, and W. Gata, "Desain Vending Machine Rujak Buah Dengan Finite State Automata," IJCIT (Indonesian J. Comput. Inf. Technol., vol. 5, no. September, pp. 198-207, 2020.

[7] E. Erni, F. Titiani, S. A. Putri, and W. Gata, "Penerapan Konsep Finite State Automata Pada Aplikasi Simulasi Vending Machine Jamu Tradisional," J. Inform., vol. 7, no. 2, pp. 141-147, 2020, doi: 10.31294/ji.v7i2.8151.

[8] F. A. Ririn Suharsih, "Penerapan Konsep Finite State Automata (FSA) pada Aplikasi Simulasi Vending Machine Yoghurt Walagri," Pendidik. Multimed., vol. 1, no. 2, pp. 7177, 2019. 
[9] S. Hidayat, F. Said, F. Titiani, and W. Gata, "Desain Konsep Finite State Automata (Fsa) Pada Simulasi Vending Machine (Vm) Masakan Padang," J. Inf. Syst. Informatics Comput., vol. 5, no. 1, p. 134, 2021, doi: 10.52362/jisicom.v5i1.442.

[10] B. Richardson, K. Hendy, V. Andiyani, and W. Philips, "Penerapan Konsep NonDeterministic Finite Automata (NFA) pada Aplikasi Simulasi Mesin Kopi Vending," J. Inform. Univ. Pamulang, vol. 4, no. 1, p. 1, 2019, doi: 10.32493/informatika.v4i1.2062.

[11] A. Faisal, G. V. Saragih, and W. Gata, "Desain Vending Machine Rokok Dengan Mengimplementasikan Finite State Automata Terintegrasi Dengan E-KTP," Matics, vol. 12, no. 1 , p. 55,2020 , doi: $10.18860 /$ mat.v12i1.8693.

[12] A. P. Giovani, F. Zamachsari, E. D. Agustono, M. I. Prasetya, and W. Gata, "Implementasi Finite State Automata Dalam Siklus Pembelajaran Magister IImu Komputer STMIK Nusa Mandiri," CESS (Journal Comput. Eng. Syst. Sci., vol. 5, no. 2, p. 221, 2020, doi: 10.24114/cess.v5i2.16696.

[13] T. H. Wicaksono, F. D. Amrizal, and H. A. Mumtahana, "Pemodelan Vending Machine dengan Metode FSA (Finite State Automata)," DoubleClick J. Comput. Inf. Technol., vol. 2, no. 2, pp. 66-69, 2019.

[14] T. I. Saputra, F. Fauziah, and A. Gunaryati, "Simulasi Vending Machine Dengan Mengimplementasikan Finite State Automata," JOINTECS (Journal Inf. Technol. Comput. Sci., vol. 3, no. 3, pp. 143-148, 2018, doi: 10.31328/jointecs. V3i3.819.

[15] R. Prahardis, D. Syauqi, and S. R. Akbar, "Implementasi Sistem Monitoring Polusi Udara Berdasarkan Indeks Standar Pencemaran Udara Dengan Pemodelan Finite State Machine," J. Pengemb. Teknol. Inf. dan IImu Komput., vol. 2, no. 9, 2018.

[16] D. D. Aryarajendra Suprapto and F. Fauziah, "Implementasi Finite State Automata pada Mesin Abstrak DFA dan NFA Berbasis Android," STRING (Satuan Tulisan Ris. dan Inov. Teknol., vol. 5, no. 1, p. 28, 2020, doi: 10.30998/string.v5i1.6196.

[17] M. Sipser, Introduction to the Theory of Computation, 3rd ed. Boston, 2013.

[18] N. L. Z. Sahrul, Fitri Karimah, Alzahid Muhazabah, Aries Dwi Prasetyo, Ariana Yunita, "Pengembangan Aplikasi Permainan 'Pilah Sampah' Menggunakan Pemodelan Finite State," Jurnal Teknologia, vol. 1, no. 1, pp. 38-46, 2018. 